\title{
IMPACT OF RUNOFF ON SALT INTRUSION OF YANGTZE ESTUARY
}

\author{
Tilai $\mathrm{Li}^{1}$, Xiangyu $\mathrm{Gao}^{2}$, Xinzhou Zhang ${ }^{3}$, Yinshuang Wang ${ }^{4}$
}

\begin{abstract}
Based on one-dimensional and two-dimensional mathematical coupling models of tidal current and salinity from Datong to Yangtze estuary, the impacting scope of salt intrusion are calculated when the runoff of Datong from $4,500 \mathrm{~m}^{3} / \mathrm{s}$ to $30,000 \mathrm{~m}^{3} / \mathrm{s}$, and the maximum and average value of salinity at each representative point of the estuary are given. When flow of Datong is less than $10,000 \mathrm{~m}^{3} / \mathrm{s}$, if projects of water transfer, pumping and diversion are not taken into account at the lower reaches of Datong, the maximum salinity at the downstream reaches of Xuliujing and the average salinity at the downstream reaches of Baimaosha will exceed drinking water criteria.
\end{abstract}

Keywords: runoff; salt intrusion; Yangtze estuary; mathematical coupling model

\section{OVERVIEW OF YANGTZE RIVER ESTUARY}

The Yangtze River is the largest river in China and the third largest in the world. Yangtze Estuary is a typical sand bar and three-order branches tidal estuary. The tidal limit is situated between Tongling and Wuhu of Anhui Province, about 640km away from the estuary. The tidal current limit is at the lower reaches of Jiangyin of Jiangsu Province, about 240km away from the estuary (Fig. 1).

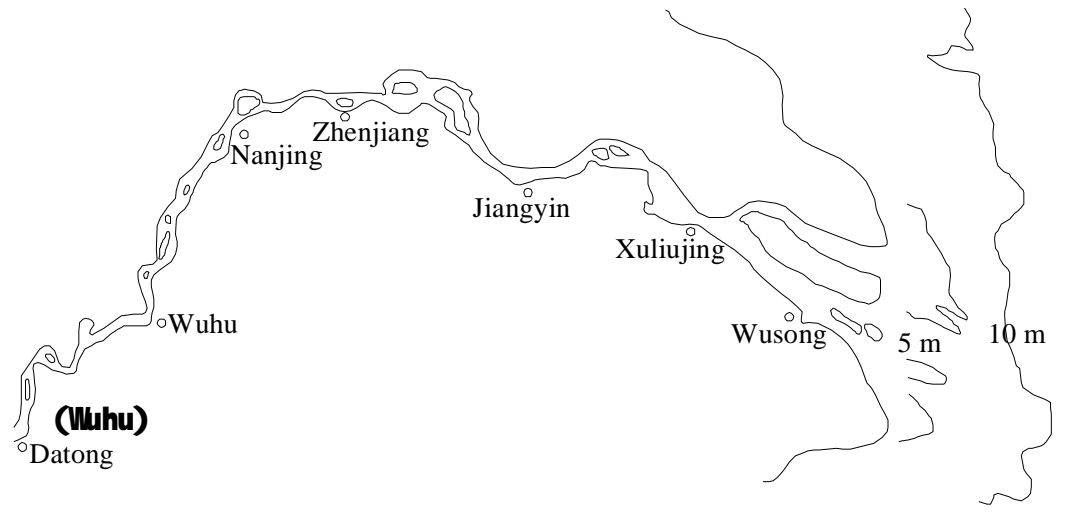

Figure 1. Schematic Diagram of the Estuary Section of Yangtze River

Yangtze Estuary is a place where salt water and fresh water meet. Some major change of the river exerts certain influence on the estuary. Since the 1950s, 48,000 reservoirs have been built at the basin of the Yangtze River, with a total capacity up to 120 billion $\mathrm{m}^{3}$. The completion of water conservancy projects will change river runoff and the former seasonal distribution. For example, after the Three Gorges Project is completed, the annual drainage won't change obviously but the seasonal distribution of runoff greatly changes. The total transferred water volume in the east, middle and west routes of the South-to-North Water Diversion Project is about 40 billion $\mathrm{m}^{3} / \mathrm{a}$, equal to $4 \%$ of annual runoff of the Yangtze River. Besides, it is planned to conduct cascade development on the trunks and branches of the upper reaches and a series of diversion projects at the lower reaches. The implementation and overlapping impact of these water conservancy projects will directly affect the change of hydrological regime of the estuary. What's more, some environmental factors related to runoff such as sediment discharge, concentration of nutritious substances, water quality and self-cleaning capacity of water body, will change subsequently. These changes will affect the habitat of aquatic organisms at the

\footnotetext{
${ }^{1}$ River and Harbor Engineering Department, Nanjing Hydraulic Research Institute (NHRI), 223 Guangzhou Road, Nanjing, 210029, China

${ }^{2}$ River and Harbor Engineering Department, Nanjing Hydraulic Research Institute (NHRI), 223 Guangzhou Road, Nanjing, 210029, China

${ }^{3}$ River and Harbor Engineering Department, Nanjing Hydraulic Research Institute (NHRI), 223 Guangzhou Road, Nanjing, 210029, China

${ }^{4}$ Department of Environmental science and Engineering,Hohai University,1 Xikang Road, Nanjing, 210024, China
} 
estuary and coastal zone and change the structure, composition, distribution characteristics and productivity of biocommunity.

\section{Runoff}

Datong Station is an important hydrological station at the downstream of the Yangtze River and the tidal limit of Yangtze Estuary. According to statistical of 1950 2001 at Datong Station, there is plenty of water at Yangtze Estuary, with average runoff of 903.6 billion $\mathrm{m}^{3}$, average flow of $28,630 \mathrm{~m}^{3} / \mathrm{s}$ and average peak discharge of $56,200 \mathrm{~m}^{3} / \mathrm{s}$ in many years. The maximum peak discharge is $92,600 \mathrm{~m}^{3} / \mathrm{s}$ and the minimum low flow is $4,620 \mathrm{~m}^{3} / \mathrm{s}$. The runoff in flood season (May to Oct.) accounts for $70.9 \%$ of yearly runoff; the runoff in dry season (Nov. to April of the next year) takes up $29.1 \%$ of the whole year.

\section{Tide and Current}

There is irregular semidiurnal tide, with medium strength and average range of $2.67 \mathrm{~m}$. Tidal wave at the estuary is mixed wave dominated by progressive wave. During the spreading process, the front of the tidal wave gradually becomes steep and the rear gradually becomes gentle. The duration of flood tide from the outside to the inside of the estuary gradually decreases and that of ebb tide gradually increases. The tide level becomes higher and higher upstream while the tidal range becomes smaller and smaller upstream.

Tidal quantity of Yangtze Estuary changes with the astronomical tide and the upstream runoff. Under the circumstance that upstream runoff is close to average annual flow and tidal range outside the estuary approaches the average tidal range, the estuary tidal influx reaches up to $263,000 \mathrm{~m}^{3} / \mathrm{s}$. The tidal influxes of spring tide in dry season, of neap tide in dry season, of spring tide in flood season and of neap tide in flood season are about 3.9 billion $\mathrm{m}^{3}, 1.3$ billion $\mathrm{m}^{3}, 5.3$ billion $\mathrm{m}^{3}$ and 1.6 billion $\mathrm{m}^{3}$, respectively.

\section{Salinity}

According to the national investigation in 1959, influenced by runoff and ocean current, $30 \%$ o salinity outside Yangtze Estuary can extend to east of $125^{\circ}$ east longitude in flood season and at around east longitude $122^{\circ} 30^{\prime}$ in dry season with changing scope up to $300 \mathrm{~km}$. Analyzed the measured data, the maximum change of the runoff can be up to 20 times and about 7 times within one year, and with relative large change of tide range.

As a whole, Yangtze Estuary are characterized in that the salinity in dry season is more than that in flood season, that in Northern Branch is higher than that in Southern Branch and that outside the estuary is higher than that in the inside. The distribution of salinity shows obvious change in terms of time and space. The daily changing process of salinity is basically similar to tide level process, two highs and two lows appearing in one day with obvious daily unequal phenomenon. The salinity gradually increases from the upper to the lower reaches and dramatically increases after passing the estuary (Fig.2).
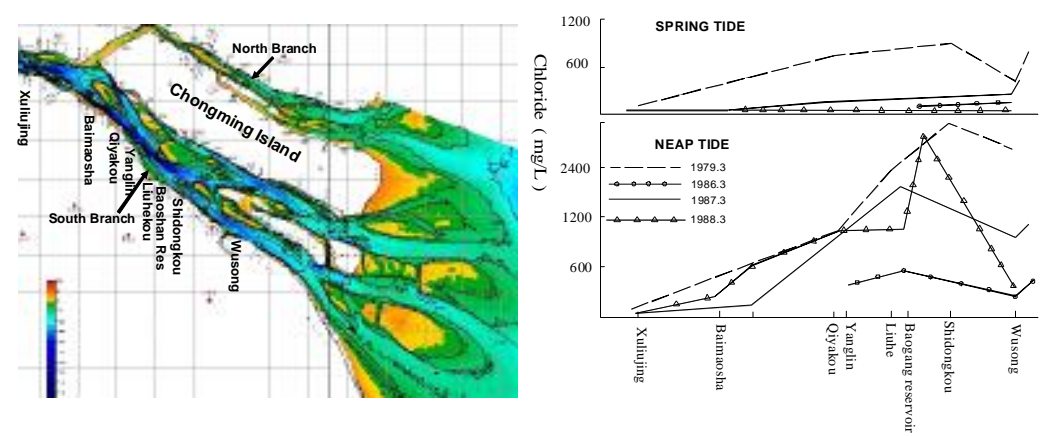

Figure 2. Distribution of Chloride Along the Route 
TIDAL CURRENT AND SALINITY MATHEMATIC MODEL

Salinity is a key factor affecting the water used for industrial and agricultural production. When salt intrusion exceeds the water quality criteria used for industrial, agricultural production and domestic drinkable water, it is hard to guarantee the safety of water supply.

Reduction of runoff is the direct reason causing increase of estuary salinity. This study adopts the technique of coupling 1D and 2D mathematic models to study the time and space changing rule of the estuary salinity intrusion.

\section{Calculation Area}

Scope of one-dimensional mathematical model: there are 335 sections from Datong to Jiangyin with a total length of around $450 \mathrm{~km}, 210$ of which are main stream sections (Fig. 3).

Scope of 2D tide salinity mathematic model: from Jiangyin in the west to the east longitude $123^{\circ}$ in the east, from north latitude $29^{\circ} 27^{\prime}$ in the south to the north latitude $32^{\circ} 15^{\prime}$ in the north, including Yangtze Estuary and Hangzhou Bay. Figure 4 is the scope of the $2 \mathrm{D}$ mathematic model. The model adopts orthogonal curvilinear grid, the number of grids is $418 \times 328=127104$, and grid size is between 50 to $2,000 \mathrm{~m}$.

The basic equtions of tide and salinity in 1D and 2D movement are expressed in refrence.Connection condition for $1 \mathrm{D}$ and $2 \mathrm{D}$ is equality of the tide level of overlapping sections and equality of flows. The tide level is controlled by $2 \mathrm{D}$ model and the flow by $1 \mathrm{D}$ model. In each step, 2D model calculation is made prior to 1D model calculation.

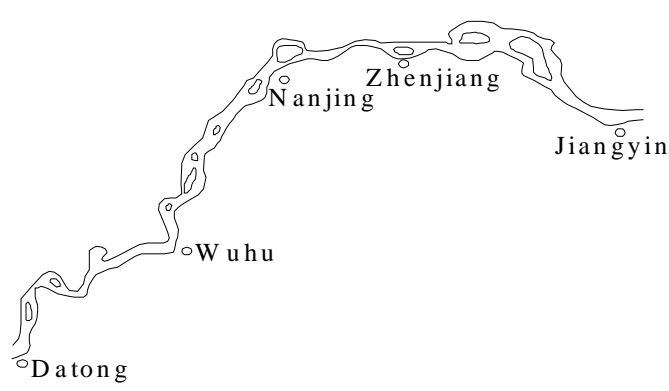

Figure 3. Schematic Diagram of 1D Tide Model Section from Datong to Jiangyin

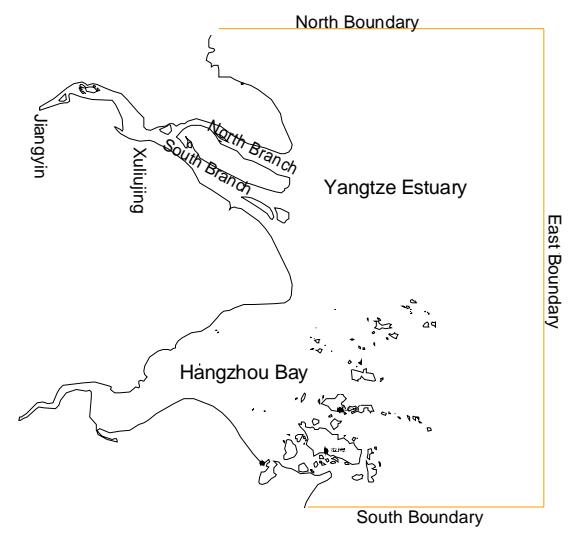

Figure 4. Scope of 2D Model for Yangtze Estuary

\section{Tidal Current Model Calibration and Verification}

The out sea boundary, the north boundary and south boundary is controlled by tidal level from a model of the East China Sea. The upstream boundary is controlled by flow discharge at Datong Station. The value of roughness is taken between 0.012 to 0.022 . The turbulent viscosity is $30 \mathrm{~m}^{2} / \mathrm{s}$. The time step is $4 \mathrm{~s}$. 
Calibration is carried out by adopting tide level data and data of velocity and direction of flow of spring tide, median tide and neap tide in September 2002, with the result omitted. After calibration, the data measured in Febuary and March 2002 are used for verification. The values taken for each parameter are the same as those at calibration.

The tide levels are verified from Datong to Jiangyin according to the data of Wuhu, Nanjing, Zhenjiang and Jiangyin from February 25 to March 6, 2002.

The velocity and direction of tide currents are also verified by the data of spring tide, median tide and neap tide measured in March, 2002. The verification results are omitted due to the limitation of length.

\section{Salinity Model Calibration and Verification}

The out sea boundary of salinity model is given by the measured data. For closed boundary, normal gradient of salinity is taken as zero. Initial condition for calculation is interpolated linearly according to the measured value. Salinity field distribution obtained from above 200-hour calculation of model is the initial salinity field. Diffusion coefficient of salinity is taken as $10 \mathrm{~m}^{2} / \mathrm{s}$.

Salinity is calibrated according to the measured values from 10:00 on September 22, 2002 to 13:00 on September 23, 2002 (spring tide), 21:00 on September 26, 2002 to 1:00 on September 28, 2002 (mean tide) and from 10:00 on September 29, 2002 to 14:00 on September 30, 2002 (neap tide). Verification of the model is made according to the measured salinity from 10:00 on March 1, 2002 to 14:00 March 2, 2002 (spring tide), 14:00 on March 4 to 17:00 on March 5 (mean tide), and 19:00 on March 8 to 23:00 on March 9 (neap tide). The calibration and verification results are omitted.

\section{RELATIONSHIP BETWEEN RUNOFF AND SALT INTRUSION}

In order to study the relationship between the Yangtze River runoff into the sea and the salt intrusion of Yangtze Estuary, the established 1D and 2D coupling tide and salinity mathematic models are used to calculate the salinity of Yangtze Estuary. When the runoff at Datong Station is $4,500 \mathrm{~m}^{3} / \mathrm{s}, 7,000 \mathrm{~m}^{3} / \mathrm{s}, 8,000 \mathrm{~m}^{3} / \mathrm{s}, 9,000 \mathrm{~m}^{3} / \mathrm{s}, 10,000 \mathrm{~m}^{3} / \mathrm{s}, 15,000 \mathrm{~m}^{3} / \mathrm{s}$ and $30,000 \mathrm{~m}^{3} / \mathrm{s}$, respectively, without considering the amount of water pumped and diverted at the lower river sections, the condition of Yangtze estuary salt intrusion is simulated and the maximum and average value of salinity at each control point are given.

Under the condition that the water of the Yangtze River is not pumped or diverted at the downstream of Datong, when the runoff at Datong Station is between $4,500 \mathrm{~m}^{3} / \mathrm{s}$ and $7,000 \mathrm{~m}^{3} / \mathrm{s}$, the salinity at Xuliujing is $0.19 \%{ }_{0} \sim .15 \%$, around the critical value of standard for water usage (according to standard of Shanghai Tap Water Company, Table 1); the average salinity of Wangyuhekou at the upper reaches and Tiansheng Port is less than the standard for water usage but can meet the requirement for industrial use, paddy seedling raising, irrigation and plant salt tolerance. However, the salinity from the lower reaches of Xuliujing to the estuary exceeds the standard. At the lower sections of Xuliujing, there are industrial and domestic water in-takes, which influences the water in-taking safety of Chenhang Reservoir and Baogang Reservoir(Table 2 and 3).

When Datong flow is between $7,000 \mathrm{~m}^{3} / \mathrm{s}$ to $10,000 \mathrm{~m}^{3} / \mathrm{s}$, the maximum salinity at Xuliujing is between 1.00 to $1.11 \%$ and can meet the requirement for general irrigation and vegetation safety, but the safety for drinking water and industrial water can not be guaranteed. Meanwhile, the maximum salinity at the downstream of Xuliujing can not meet the standard for other water usages, except meeting the aquatic organisms. The average salinity of Xuliujing can meet the demand for several water usages. When Datong flow is higher than $10,000 \mathrm{~m}^{3} / \mathrm{s}$, the water at Xuliujing basically meets the requirement for various water usages.

\begin{tabular}{|l|l|l|}
\hline Table 1 Standard of Water Used for Industry and Agriculture \\
\hline Name & $\begin{array}{l}\text { Industrial and agricultural water } \\
(\mathrm{mg} / \mathrm{L})\end{array}$ & $\begin{array}{l}\text { Industrial and agricultural water } \\
(\%)\end{array}$ \\
\hline $\begin{array}{l}\text { Standard of saltwater intrusion of } \\
\text { Shanghai Water Works Co, Ltd. }\end{array}$ & $\leq 100$ & $\leq 0.18$ \\
\hline Maximum value by Baosteel Group & 200 & 0.36 \\
\hline Standard for raising paddy seedling & $\leq 600$ & $\leq 1.08$ \\
\hline Standard for general irrigation water & $\leq 1100$ & $\leq 1.98$ \\
\hline $\begin{array}{l}\text { Maximum concentration for plant safe } \\
\text { water usage }\end{array}$ & 3150 & 6.3 \\
\hline
\end{tabular}

Note: Salinity $\mathrm{S} \%=1.80655 \mathrm{Cl} \%$; $\mathrm{Cl}$ stands for chlorinity 


\begin{tabular}{|c|c|c|c|c|c|c|c|}
\hline Runoffs & $\begin{array}{l}\text { Upstream of } \\
\text { Tiansheng Port }\end{array}$ & Wangyuhekou & Xuliujing & Baimaosha & Langgang & Liuhekou & $\begin{array}{l}\text { Chenhang } \\
\text { Reservoir }\end{array}$ \\
\hline 4,500 & 0.02 & 0.15 & 1.47 & 3.04 & 8.71 & 7.11 & 6.82 \\
\hline 7,000 & 0.02 & 0.06 & 1.11 & 2.02 & 5.13 & 4.301 & 4.14 \\
\hline 8,000 & 0.02 & 0.06 & 1.10 & 2.01 & 5.06 & 4.27 & 4.12 \\
\hline 9,000 & 0.02 & 0.06 & 1.06 & 1.94 & 5.01 & 4.22 & 4.06 \\
\hline 10,000 & 0.02 & 0.06 & 1.00 & 1.83 & 4.86 & 4.12 & 3.96 \\
\hline 15,000 & 0.02 & 0.02 & 0.10 & 0.20 & 0.41 & 0.39 & 0.38 \\
\hline 30,000 & 0.02 & 0.02 & 0.03 & 0.03 & 0.04 & 0.05 & 0.05 \\
\hline
\end{tabular}

Note: Italics refer to salinity exceeding the standard.

\begin{tabular}{|c|c|c|c|c|c|c|c|}
\hline Runoffs & $\begin{array}{l}\text { Upstream of } \\
\text { Tiansheng Port }\end{array}$ & Wangyuhekou & Xuliujing & Baimaosha & Langgang & Liuhekou & $\begin{array}{l}\text { Chenhang } \\
\text { Reservoir }\end{array}$ \\
\hline 4,500 & 0.02 & 0.04 & 0.19 & 0.96 & 5.58 & 5.55 & 5.31 \\
\hline 7,000 & 0.02 & 0.02 & 0.15 & 0.64 & 3.47 & 3.41 & 3.28 \\
\hline 8,000 & 0.02 & 0.02 & 0.14 & 0.62 & 3.44 & 3.41 & 3.29 \\
\hline 9,000 & 0.02 & 0.02 & 0.14 & 0.59 & 3.36 & 3.34 & 3.22 \\
\hline 10,000 & 0.02 & 0.02 & 0.13 & 0.56 & 3.22 & 3.23 & 3.11 \\
\hline 15,000 & 0.02 & 0.02 & 0.03 & 0.06 & 0.31 & 0.35 & 0.35 \\
\hline 30,000 & 0.02 & 0.02 & 0.02 & 0.02 & 0.03 & 0.04 & 0.04 \\
\hline
\end{tabular}

Note: Italics refer to salinity exceeding the standard.

If the pumped water in the eastern route of South-to-North Water Diversion project and other pumped and diverted water amount are taken into consideration, this part of flow discharge should be added to Datong flow.

\section{CONCLUSION}

Based on the analysis on the hydrodynamic force and salinity distribution of Yangtze Estuary and the impact of the water conservancy project at the upper reaches of the Yangtze River on the estuary runoff change, calculation is made of the salt intrusion of different incoming runoffs at Yangtze Estuary by means of one-dimensional and two-dimensional coupling tide salinity mathematic models and the conclusions are drawn as follows.

One-dimensional and two-dimensional tide salinity mathematic models are established for Yangtze Estuary. The verification shows that the model can simulate the movement of spring tide, mean tide and neap tide in flood and dry seasons at Yangtze Estuary, which reflects the currents be clockwise rotation at the estuary and reciprocating inside the estuary. The calibration calculation of saltwater mathematic model indicates that the model can reflect the movement characteristics of salt intrusion and from Northern Branch salt.

Through the calculation of tide and salinity mathematic model, the impact scope and degree of saltwater intrusion are acquired under seven conditions of the runoff of Datong $4,500 \mathrm{~m}^{3} / \mathrm{s}, 7,000 \mathrm{~m}^{3} / \mathrm{s}$, $8,000 \mathrm{~m}^{3} / \mathrm{s}, 9,000 \mathrm{~m}^{3} / \mathrm{s}, 10,000 \mathrm{~m}^{3} / \mathrm{s}, 15,000 \mathrm{~m}^{3} / \mathrm{s}$ and $30,000 \mathrm{~m}^{3} / \mathrm{s}$, respectively. When Datong flow discharge is less than $10,000 \mathrm{~m}^{3} / \mathrm{s}$, without considering water transfer, pumping and diversion projects at the downstream of Datong, both the maximum value of salinity at the downstream of Xuliujing and the average value of salinity at the downstream of Baimaosha exceed drinking water standard.

\section{ACKNOWLEDGMENTS}

The peoject is financially supported by the National Science and Technology Supporting Plan of The Eleventh Five-year (Grant No. 2008BAB42B08) \& Ministry of Water Resources' Special Funds for Scientific Research on Public Causes (Grant No. 200801008; 2007Shz02(1-9). The writers benifitted greatly from stimulating discussions with Xiping Dou.

\section{REFERENCES}

Li Tilai, Gao Xiangyu, Wang Yinshuang. 2009.Impact of Changes in Runoff into the Sea on Saltwater Intrusion of Yangtze Estuary, Proceeding of 14th Chinese Coastal Engineering Conference, Huhhot, Inner Mogolia Autonomous Region, China,917 -926.

Luo Bingzheng, Sheng Huanting. 1994.The Three Gorges Project and Estuary Ecological Environment. Chinese Science Press, Beijing. 
Mao Zhichang, et al. 2001. Saltwater Intrusion Patterns in the Qingcaosha Area Changjiang River Eetuary, Oceanologia Et Limnologia Sinica,Vol.32, No.1,58-66.

Song Zhirao, Mao Lihua. 2002. Study of Yangtze Estuary Saltwater Intrusion, Protection of Water Resources, No3.,27-30

Xiao Chengyou, et al. 2000.Digit Model Study of Saltwater Encroachment of the Northern Branch of Yangtze Estuary, Journal of Oceanography, 22 (5),124-132.

Zhang Erfeng, Chen Xiqing. 2001.Change of Dry Season Water Level Flow at Yangtze River Datong - Estuary Section, Journal of Geological Sciences, Vol. 2, 231-238. 